\title{
Blockade of Nogo-66, Myelin-Associated Glycoprotein, and Oligodendrocyte Myelin Glycoprotein by Soluble Nogo-66 Receptor Promotes Axonal Sprouting and Recovery after Spinal Injury
}

\author{
Shuxin Li, ${ }^{1}$ Betty P. Liu, ${ }^{1}$ Stephane Budel, ${ }^{1}$ Mingwei Li, ${ }^{2}$ Benxiu Ji, ${ }^{2}$ Lee Walus, ${ }^{2}$ Weiwei Li, ${ }^{2}$ Adrienna Jirik, ${ }^{2}$ \\ Sylvia Rabacchi, ${ }^{2}$ Eugene Choi, ${ }^{2}$ Dane Worley, ${ }^{2}$ Dinah W. Y. Sah, ${ }^{2}$ Blake Pepinsky, ${ }^{2}$ Daniel Lee, ${ }^{2}$ Jane Relton, ${ }^{2}$ and \\ Stephen M. Strittmatter ${ }^{1}$ \\ ${ }^{1}$ Departments of Neurology and Neurobiology, Yale University School of Medicine, New Haven, Connecticut 06510, and 2BiogenIdec, Inc., Cambridge, \\ Massachusetts 02140
}

\begin{abstract}
The growth of injured axons in the adult mammalian CNS is limited after injury. Three myelin proteins, Nogo, MAG (myelin-associated glycoprotein), and OMgp (oligodendrocyte myelin glycoprotein), bind to the Nogo-66 receptor (NgR) and inhibit axonal growth in vitro. Transgenic or viral blockade of $\mathrm{NgR}$ function allows axonal sprouting in vivo. Here, we administered the soluble function-blocking $\mathrm{NgR}$ ectodomain [aa 27-310; $\mathrm{NgR}(310)$ ecto] to spinal-injured rats. Purified $\mathrm{NgR}(310)$ ecto-Fc protein was delivered intrathecally after midthoracic dorsal over-hemisection. Axonal sprouting of corticospinal and raphespinal fibers in NgR(310)ecto-Fc-treated animals correlates with improved spinal cord electrical conduction and improved locomotion. The ability of soluble $\mathrm{NgR}(310)$ ecto to promote axon growth and locomotor recovery demonstrates a therapeutic potential for $\mathrm{NgR}$ antagonism in traumatic spinal cord injury.
\end{abstract}

Key words: spinal cord; axon; Nogo; Nogo-66 receptor; serotonin; magnetic stimulation

\section{Introduction}

After CNS injury, the growth of injured and spared axons has the potential to restore function. The restorative potential of axon growth is most obvious in spinal cord injury (SCI). Axon growth in the adult mammalian CNS is inhibited in part by myelinderived inhibitors (Schwab and Caroni, 1988; Savio and Schwab, 1989; McGee and Strittmatter, 2003) and in part by glial scarderived chondroitin sulfate proteoglycans (Snow et al., 1990; Davies et al., 1999; Bradbury et al., 2002). Several of the myelin inhibitory proteins, including Nogo-A (Fournier et al., 2001), myelin-associated glycoprotein (MAG) (Domeniconi et al., 2002; Liu et al., 2002), and oligodendrocyte myelin glycoprotein (OMgp) (Curristin et al., 2002; K. C. Wang et al., 2002a), can signal to the Nogo-66 receptor $(\mathrm{NgR})$. The structure of the ligand-binding domain of the $\mathrm{NgR}$ has been determined (Barton et al., 2003; He et al., 2003) but requires a second domain for effective signaling of axon growth inhibition (Fournier et al.,

Received July 14, 2004; revised Sept. 2, 2004; accepted 0ct. 13, 2004.

This work was supported by grants from the Christopher Reeve Paralysis Foundation and the Institut International de Recherche en Paraplegie, Geneva, to S.L. and from the National Institutes of Health to S.M.S. We thank Yiguang Fu and Ji Liao for expert technical assistance with in vivo studies. We also thank Raymond Boynton, Azita Kaffashan, Konrad Miatkowski, Maria Slight, and Rich Tizard for technical assistance.

Correspondence should be addressed to Dr. Stephen M. Strittmatter, Department of Neurology, Yale University School of Medicine, P.0. Box 208018, New Haven, CT 06510. E-mail: stephen.strittmatter@yale.edu.

DOI:10.1523/JNEUROSCI.2828-04.2004

Copyright $\odot 2004$ Society for Neuroscience ～0270-6474/04/2410511-10\$15.00/0
2002). Additional components of the NgR signaling complex can include p75-NTR and Lingo-1 (K. C. Wang et al., 2002b; Wong et al., 2002; Mi et al., 2004). In the accompanying work, we demonstrate that transgenic expression of the NgR ligand-binding domain allows axonal sprouting and improved recovery from SCI in mice (S. Li, S. Budel, J. E. Kim, T. G. Hampton, and S. M. Strittmatter, unpublished observations). Viral expression of a dominant-negative version of the NgR lacking the signaling domain promotes axonal regeneration from retinal ganglion cells (Fischer et al., 2004). Thus, NgR-mediated control of axonal growth plays a role in determining the degree of axonal growth after adult CNS injury in mammals.

Pharmacological methods to perturb the CNS myelin inhibitor system have included anti-Nogo antibodies (Schnell and Schwab, 1990; Bregman et al., 1995), a NgR antagonist peptide (GrandPre et al., 2002; Li and Strittmatter, 2003), Rho pathway inhibitors (Dergham et al., 2002; Fournier et al., 2003), and cAMP elevation (Neumann et al., 2002; Qiu et al., 2002; Nikulina et al., 2004; Pearse et al., 2004). All four methods have some efficacy in vivo. The first two approaches are specific for Nogo and do not disrupt MAG or OMgp action. Blockade of Rho signaling blocks myelin and glial scar inhibition but may modify many other forms of cellular motility. Alterations of cAMP signaling may also have pleiotropic effects on numerous signaling pathways.

Here, we have sought to administer the function-blocking soluble $\mathrm{NgR}$ protein fragment intrathecally in rat SCI. We find 
that the degree of axonal sprouting is more robust than with Nogo-66-specific antagonist peptide treatment (GrandPre et al., 2002; Li and Strittmatter, 2003). Furthermore, we show that improved recovery of electrophysiological function parallels axonal sprouting and behavioral improvement after SCI.

\section{Materials and Methods}

$\mathrm{NgR}$ binding studies. Microtiter well binding assays were performed as described previously (Barton et al., 2003). Each well was coated with 0.5 $\mu \mathrm{g}$ of purified NgR protein. Binding of $100 \mathrm{~nm}$ AP-Nogo-66, AP-MAG, or AP-OMgp was assessed in the presence of $25 \mu \mathrm{g}$ of $\mathrm{NgR}(310)$ ecto-Fc or $100 \mu \mathrm{g}$ of NEP1-40 peptide after $4 \mathrm{hr}$ at $23^{\circ} \mathrm{C}$ (Barton et al., 2003).

Preparation of $\mathrm{NgR}(310)$ ecto-Fc protein. The cDNA encoding the first 310 amino acid residues of rat NgR1 was cloned by PCR from the adult rat brain Marathon-Ready cDNA (Clontech, Cambridge, UK) with oligomers 5'-GAATAGCGGCCGCGCCGCCACCATGAAGAGGGCGTCCTCCGGAGG-3' (including nucleotides 1-23 of GenBank accession number AF462390) and 5' -ATAATGCGGCCGCTCAAGCACAACCCTGTAAGTCACTGGC-3' (including the complement of nucleotides 907-930 of GenBank accession number AF462390). This cDNA fragment was fused to the cDNA encoding the hinge and Fc region of rat IgG1 $[\mathrm{NgR}(310)$ ecto-Fc] in the mammalian stable expression vector PV90. The nucleotide sequence was confirmed by DNA sequencing, and $\mathrm{NgR}(310)$ ecto-Fc was expressed in Chinese hamster ovary (CHO)-DG44 cells. A high expressor clone $(\sim 10 \mathrm{mg} / \mathrm{l}$, as determined using an anti-rat Fc ELISA) was chosen for large-scale cell culture in BCM16 medium ( 80 1). The culture supernatant obtained was concentrated $\sim 10$-fold using a spiral cartridge concentrator (30 kDa cutoff; Millipore, Bedford, MA) and filtered. Tris- $\mathrm{HCl}(1.0 \mathrm{M}, \mathrm{pH} 8.9), \mathrm{NaCl}$, and glycine were added to the filtered supernatant to a final concentration of $100 \mathrm{~mm}$ Tris- $\mathrm{HCl}, \mathrm{pH}$ $8.9,3 \mathrm{M} \mathrm{NaCl}$, and $1.5 \mathrm{M}$ glycine. This was loaded to a $300 \mathrm{ml}$ protein A-Sepharose column (Pharmacia Biosciences, Piscataway, NJ), and the column was washed with two column volumes of binding buffer $(100 \mathrm{~mm}$ Tris- $\mathrm{HCl}, \mathrm{pH} 8.9,3 \mathrm{M} \mathrm{NaCl}$, and $1.5 \mathrm{~m}$ glycine), followed by one column volume of $5 \mathrm{~mm}$ Tris- $\mathrm{HCl}$ and $3 \mathrm{~m}$ sodium chloride, $\mathrm{pH}$ 8.9. $\mathrm{NgR}(310)$ ecto-Fc was eluted with $25 \mathrm{~mm}$ phosphate, $\mathrm{pH} 2.8,100 \mathrm{~mm}$ $\mathrm{NaCl}$, and neutralized with one-tenth volume of $0.5 \mathrm{M}$ sodium phosphate, $\mathrm{pH}$ 8.6. The eluted protein was dialyzed against PBS, filtered, aliquoted, and stored at $-70^{\circ} \mathrm{C}$. Purity was $>95 \%$ as assessed by SDSPAGE, and, as expected, the N-terminal sequence began with cysteine residue 27. Under reducing and nonreducing SDS-PAGE, $\operatorname{NgR}(310)$ ecto-Fc had apparent masses of 60 and $120 \mathrm{kDa}$, respectively. The endotoxin level in the product was $<4$ endotoxin units/mg. NgR(310)ecto-Fc binds directly to ${ }^{125} \mathrm{I}-\mathrm{Nog} 066$, AP-Nogo66, glutathione S-transferaseNogo66, and MAG-Fc; blocks the binding of the individual myelin proteins (Nogo, MAG, and OMgp) to NgR1 expressed on cells; and enhances neurite outgrowth in rat dorsal root ganglia [postnatal day 4 (P4) to P7] and cerebellar granule neurons (P10-P12) cultured on a bovine CNS myelin substrate.

Rat SCI and NgR(310)-Fc administration. Female Sprague Dawley rats (190-250 gm) were deeply anesthetized with ketamine $(60 \mathrm{mg} / \mathrm{kg})$ and xylazine $(10 \mathrm{mg} / \mathrm{kg})$. Laminectomy was conducted at spinal levels of T6 -7 , and the spinal cord was exposed. The dorsal half of the spinal cord was cut with a 30 gauge needle and a pair of microscissors to sever the dorsal parts of corticospinal tracts (CSTs), and the depth of the lesion $(1.8 \mathrm{~mm})$ was assured by passing the sharp part of a number 11 blade across the dorsal half of the cord (GrandPre et al., 2002). An osmotic minipump (Alzet 2ML4; $2 \mathrm{ml}$ volume, $2.5 \mu \mathrm{l} / \mathrm{hr}$, $28 \mathrm{~d}$ delivery), which was filled with $1.2 \mathrm{mg}$ of rat IgG in PBS or $1.2 \mathrm{mg}$ of $\mathrm{NgR}(310)$ ecto-Fc fusion protein in PBS, was sutured to muscles under the skin on the back of the animals. A catheter connected to the outlet of the minipump was inserted into the intrathecal space of the spinal cord at the T7-8 level through a small hole in the dura.

Rat CST tracing and 5,7-dihydrotryptamine injection. For the rats receiving CST tracing, a burr hole was made on each side of the skull overlying the sensorimotor cortex of the lower limbs $14 \mathrm{~d}$ after overhemisection. The anterograde neuronal tracer biotin dextran amine (BDA) (10\% in PBS; $3.5 \mu$ l per cortex) was applied at seven injection sites at a depth of $1.5 \mathrm{~mm}$ from the dura on each side (coordinates: 1.0-3.0 $\mathrm{mm}$ posterior to bregma; $1.8-3.8 \mathrm{~mm}$ lateral) (GrandPre et al., 2002). Two weeks after BDA injection, these animals were perfused with PBS, followed by $4 \%$ paraformaldehyde, and tissue was collected for histology.

For the rats receiving intracerebroventricular serotonin neurotoxin, 5,7-dihydroxytryptamine ( $105 \mu \mathrm{g}$ dissolved in $7 \mu \mathrm{l}$ of $0.2 \%$ ascorbic acid in normal saline), the tip of the glass micropipette was positioned into the right lateral cerebral ventricle (coordinates: $0.8 \mathrm{~mm}$ posterior to bregma; $1.5 \mathrm{~mm}$ lateral from the sagittal suture; $3.5 \mathrm{~mm}$ deep from the cortical surface) 3 weeks after SCI. The duration of injection lasted over $5 \mathrm{~min}$, and the micropipette was kept in position for an additional $5 \mathrm{~min}$ before withdrawal. Thirty minutes before the 5,7-dihydrotryptamine (DHT) injection, the monoamine uptake inhibitor desipramine ( $25 \mathrm{mg} / \mathrm{kg}$, i.p.), was administrated. Two weeks after DHT injections, these rats were perfused for histological examination.

Histology for BDA tracing, lesion depth, and serotonin fiber staining. For $\mathrm{NgR}(310)$ ecto-Fc injection experiments in rats, the spinal cord extending from $10 \mathrm{~mm}$ rostral to $10 \mathrm{~mm}$ caudal from the lesion site was cut parasagittally $(50 \mu \mathrm{m})$ on a vibrating microtome. Transverse sections were collected from the spinal cord $11-16 \mathrm{~mm}$ rostral to and $11-16 \mathrm{~mm}$ caudal to the injury site. The sections were incubated with avidin-biotin-peroxidase complex, and the BDA tracer was visualized by nickel-enhanced

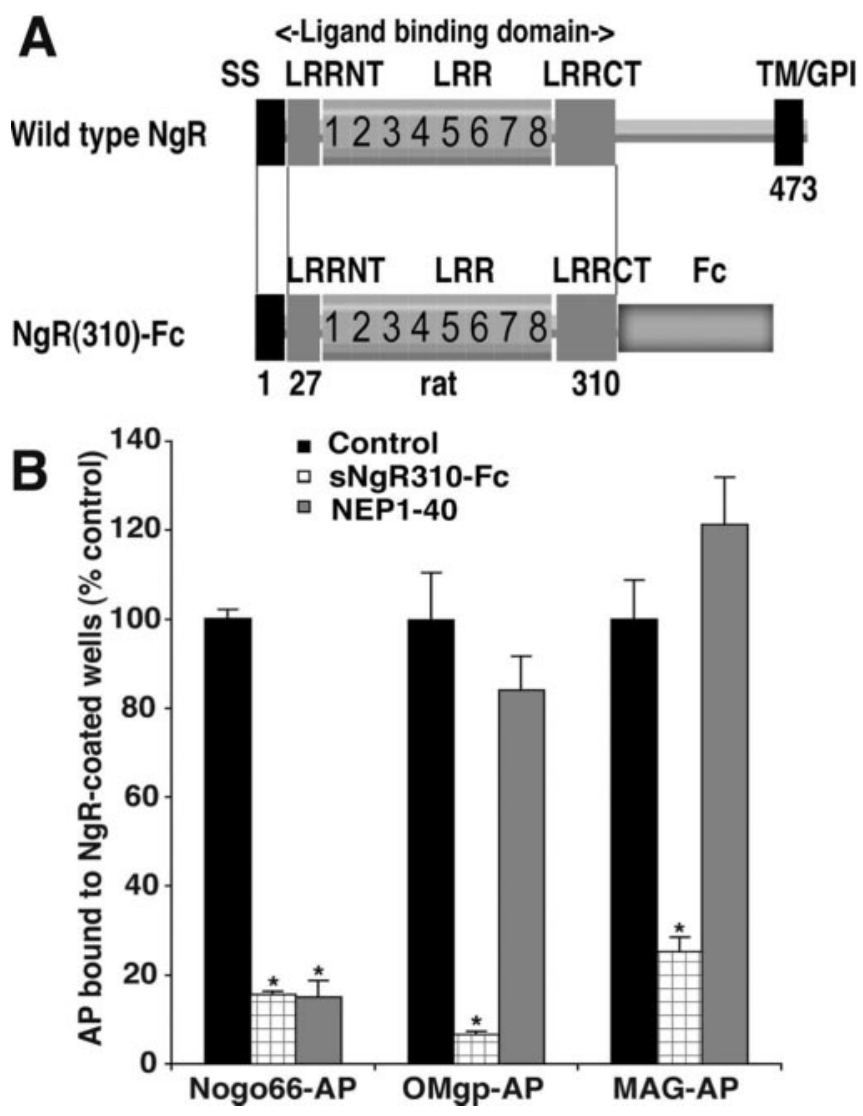

Figure 1. $\mathrm{NgR(310)Ecto-Fc} \mathrm{antagonism} \mathrm{of} \mathrm{myelin} \mathrm{inhibitors.} \mathrm{A,} \mathrm{Schematic} \mathrm{of} \mathrm{wild-type}$ $\mathrm{NgR}$ and the $\mathrm{NgR}(310)$ ecto-Fc protein for intrathecal infusion. SS, Signal sequence; LRR, leucine-rich repeat; LRRNT, LRR N-terminal cysteine-rich region; LRRCT, LRR C-terminal cysteine-rich region; TM/GPI, transmembrane/GPI anchorage site; Fc, constant region of rat $\lg G$. $B$, Soluble $\mathrm{NgR}$ antagonist $\mathrm{NgR}(310)$ ecto protein significantly blocks immobilized $\mathrm{NgR}$ binding by all the three myelin inhibitors: Nogo-66, MAG, and 0Mgp. In contrast, $\mathrm{NgR}$ antagonist NEP1-40 peptide only blocks the binding of Nogo- 66 to $\mathrm{NgR}$ but not that of MAG and OMgp. Means + SEM are reported from 6-12 determinations. The indicated values in the presence of the inhibitor were statistically different from control binding without inhibitor ( ${ }^{*} p \leq 0.01$; Student's $t$ test). 



Figure 2. Intrathecal $\mathrm{NgR}(310)$ ecto-Fc ecto stimulates $\mathrm{dCST}$ sprouting in rats rostral to an over-hemisection. $A$, Transverse sections rostral to the lesion display a similar degree of dCST labeling in both control and $\mathrm{NgR}(310)$ ecto-Fc-treated rats. These transverse sections were obtained $15 \mathrm{~mm}$ rostral to a dorsal over-hemisection site from vehicle- or NgR(310)ecto-Fc-treated (NgR-ecto) rats, as indicated. Both CSTs are labeled, and the midline is at the center of each panel; dorsal is up in all sections. Also note the increased density of ectopic sprouts lateral to the dCST in the $\mathrm{NgR}(310)$ ecto-Fc-treated animals. B, Schematic of transverse spinal cord section illustrating the $\mathrm{dCST}$ and the location of the high-magnification images in Cand D.C,D, BDA-labeled CST fiber in gray matter adjacent to the dCST from an lgG-treated rat ( $C$ ) and a $\mathrm{NgR}(310)$ ecto-Fc-treated rat (D). E, Ectopic CST fibers outside of the dCST and dICST and $\geq 100 \mu \mathrm{m}$ in length are counted from transverse sections 11-15 mm rostral to the overhemisection. Ctrl, Vehicle. Means + SEM are reported from seven to nine determinations. The indicated values in the presence of $\mathrm{NgR}(310)$ ecto-Fc were statistically different from control (** $p \leq 0.01$; Student's $t$ test).

diaminobenzidine HRP reaction or with avidin-Alexa594 (GrandPre et al., 2002). To verify the origin of caudal CST fibers in a subset of animals, the path of individual axons near the transection area was traced from a complete set of consecutive parasagittal sections. Some sections were processed for serotonin immunohistochemistry (anti-5-HT antibody; Immunostar) by indirect immunofluorescence. To examine the reinnervation of regenerating axons in the distal spinal cord, transverse sections 17-20 mm caudal to the lesion were doubly stained with BDA-synaptophysin (Sigma, St. Louis, MO), or BDA-SMI-32 (motor neuron marker; Sternberger Monoclonals, Lutherville, MD), or 5-HT-synaptophysin. To visualize the lesion area, some sections were double stained with antibody directed against GFAP (Sigma). The sections were mounted, dehydrated, and covered with mounting medium. The transection depth was measured from GFAP staining and differential interference contrast photographs from all consecutive parasagittal sections for each animal. The dorsoventral linear depth of spared and transected tissue was measured.
Serotonin fiber length in the ventral horn of transverse sections rostral or caudal to the lesion site were measured with NIH Image software. Three sections were analyzed for each animal, and the values from these sections are averaged.

Electrophysiological recordings. To measure signal conduction in motor pathways after SCI, transcranial magnetic motor-evoked potentials (tcmMEP) were measured from rats 3 and 5 weeks after injury. To record the tcmMEP, rats were anesthetized with avertin $(250 \mathrm{mg} / \mathrm{kg}$ body weight). Magnetic stimulation was delivered by positioning the center of a stimulator coil $(5 \mathrm{~cm}$ in diameter; Cadwell Laboratories, Kennewick, WA) over the cranium, $0.5 \mathrm{~cm}$ lateral to bregma. The evoked responses were recorded from the contralateral gastrocnemius muscle. Potentials evoked by electrical stimulation of spinal cord (SCEP) were also obtained from these rats immediately before they were killed. For SCEP recording, the animals were anesthetized with avertin $(250 \mathrm{mg} / \mathrm{kg})$ supplemented with ketamine $(30 \mathrm{mg} / \mathrm{kg})$ and xylazine $(5 \mathrm{mg} /$ $\mathrm{kg}$ ). Laminectomy was performed at the $\mathrm{T} 1 \mathrm{spi}-$ nal level. The spinal cord was exposed, and a small hole in the dura was made. To directly stimulate the dorsal CST (dCST) in the spinal cord at the T1 level (rostral to the SCI site), an electrical pulse (100 $\mu \mathrm{sec}, 7 \mathrm{~mA})$ was delivered to the dCST from a glass micropipette filled with saline and placed stereotaxically at a depth $1.1 \mathrm{~mm}$ from the dorsal surface of the midline of the spinal cord. The evoked signals were recorded from the exposed right sciatic nerve with hooked needle electrodes. Onset latency and amplitude for both tcmMEP and SCEP were analyzed. The stimulation threshold for tcmMEP was measured as a percentage of maximal power applied to the magnetic coil. At least five responses were recorded and averaged from each side (right and left) of each animal.

Behavioral analysis. For behavioral testing, the Basso, Beattie, and Bresnahan (BBB) locomotor scale, grid walking, and footprint analysis were performed. For grid walking, the rats were trained to walk on a wire grid $(70 \mathrm{~cm}$ long with $2.54 \mathrm{~cm}$ squares), and the number of instances in which the hindpaw dropped below the grid plane was counted. For footprint analysis, the walking patterns of hindpaws were recorded with ink during a continuous locomotion across a $90 \mathrm{~cm}$ runway, and stride length on each side and stride width were calculated (Metz et al., 2000).

\section{Results}

\section{NgR(310)ecto as a blocker of three myelin inhibitors}

Previous work had demonstrated that the NEP1-40 peptide significantly, but partially, blocks myelin inhibition of axon outgrowth (GrandPre et al., 2002). A soluble fragment of the NgR containing the ligand-binding domain is more effective in blocking myelin-dependent inhibition (Fournier et al., 2002; Liu et al., 2002). To promote stability and purification, the ligand-binding domain of rat $\mathrm{NgR}$ was fused to the rat IgG1 Fc domain (Fig. $1 \mathrm{~A}$ ). Protein was purified from stably transfected $\mathrm{CHO}$ cells. To explore the molecular basis of this differential effectiveness, the ability of these two NgR antagonists to block the binding of the AP-tagged version of Nogo-66, MAG, or OMgp to purified NgR- 
coated wells was assessed. The NEP1-40 peptide selectively blocks Nogo-66 binding to purified $\mathrm{NgR}$ without displacing MAG or OMgp (Fig. $1 B$ ). In contrast, excess soluble ectodomain of the NgR effectively prevents the binding of all three ligands to immobilized NgR protein. Thus, the soluble $\mathrm{NgR}(310)$ ecto-Fc protein provides a means to perturb simultaneously all three NgR ligands.

\section{Intrathecal $\mathrm{NgR}(310)$ ecto-Fc protein induces CST sprouting in the injured spinal cord}

As a pharmacological test of the growthpromoting benefit of $\mathrm{NgR}(310)$ ecto-Fc after spinal trauma, we administered the purified protein intrathecally. NgR(310)ecto-Fc protein was delivered intrathecally to rats with a mid-thoracic dorsal over-hemisection injury through an osmotic minipump. Because we used rat NgR fused to rat IgG-Fc, there is no definitive method to distinguish infused from endogenous protein immuoreactivity in tissue sections. Thus, it was not possible to demonstrate the distribution of infused $\mathrm{NgR}(310)$ ecto-Fc in the tissue from SCI animals. During a 4 week survival period after SCI, $1.2 \mathrm{mg}$ of $\mathrm{NgR}(310)$ ecto-Fc protein was administered locally in each rat. At the end of this period, the CST was traced by BDA injection into the cerebral cortex. The overall intensity of BDA labeling in the CST rostral to the injury is indistinguishable between the groups (Fig. $2 \mathrm{~A}$ ). Compared with the tightly bundled dCST fibers from vehicle-treated rats, sections rostral to the lesion from injured rats receiving $\operatorname{NgR}(310)$ ecto-Fc protein exhibit ectopic fibers sprouting from the dCST (Fig. 2A-D). The density of such fibers is increased fivefold by $\mathrm{NgR}(310)$ ecto-Fc treatment.

Longitudinal sections spanning the lesion site from vehicle-treated rats display no detectable CST axons or a very small number of BDA-labeled ventral CST (vCST) fibers below the lesion level (Fig. 3) (Weidner et al., 2001; GrandPre et al., 2002). Similar sections from $\mathrm{NgR}(310)$ ecto-Fc-treated rats demonstrate many BDA-labeled fibers in the caudal spinal cord (Fig. 3). This difference cannot be attributed to altered lesion depth because immunostaining for the astrocytic marker GFAP reveals that the lesion extends deeper than the central canal area (Fig. $3 A$ ). The lesion depth $(70 \%)$ and the amount of spared tissue $(30 \%)$ in control and treated groups are identical (Fig. 3B). Photomicrographs of CST fibers caudal to the transection reveal a tortuous branching course consistent with $\mathrm{NgR}(310)$ ecto-Fc-induced axon growth rather than CST sparing (Fig. 3C-I). Counts of CST fibers from sagittal sections document $\sim 20$ BDA-labeled axons at $1-2 \mathrm{~mm}$ caudal to the
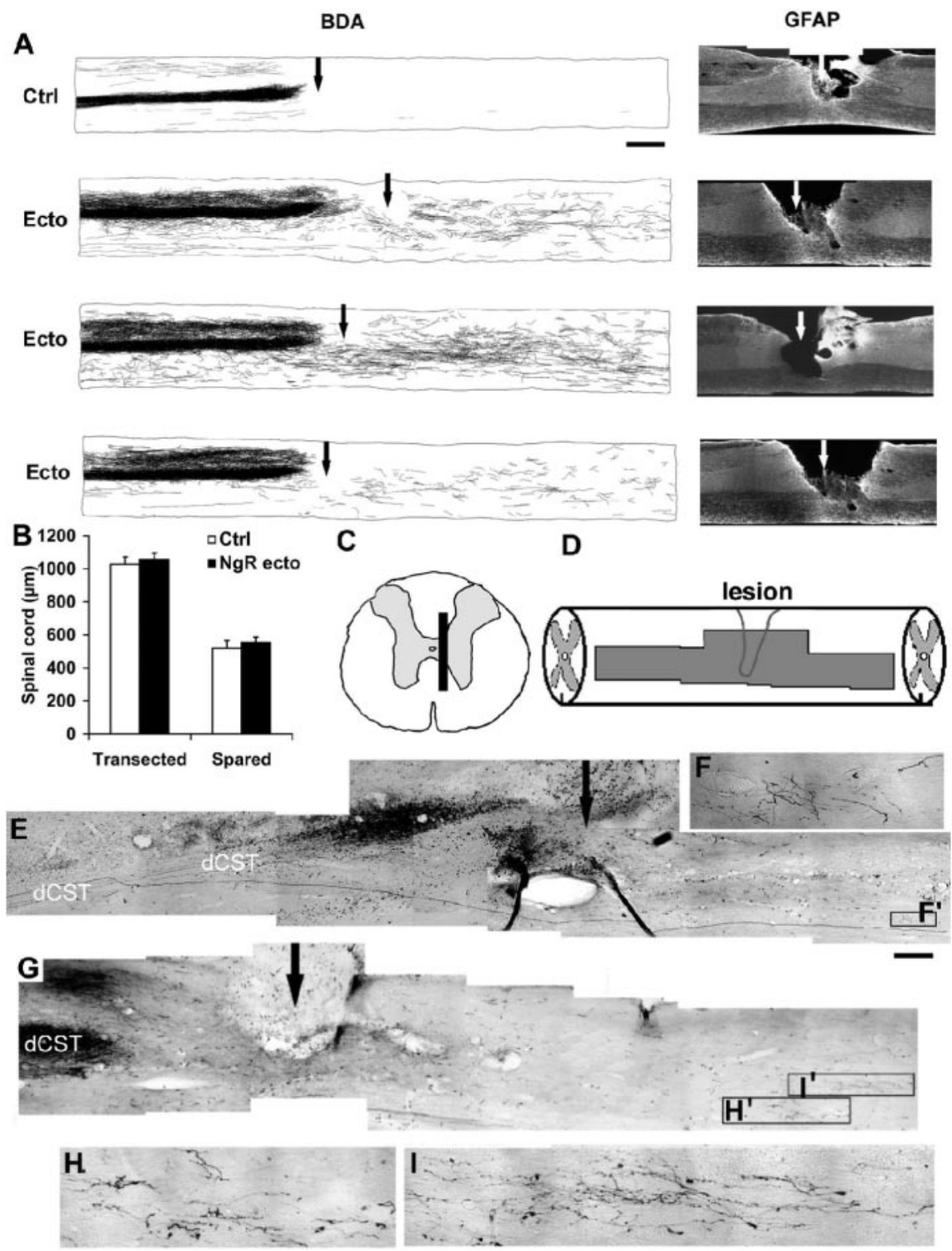

Figure 3. Local administration of soluble $\mathrm{NgR}(310)$ ecto-Fc stimulates the growth of CST fibers into the caudal spinal cord. $A$, Camera lucida drawings of CST fibers from all sagittal sections from each rat. A typical control (Ctrl) animal shows a few vCST fibers in the distal spinal cord. Three separate $\mathrm{NgR}(310 \mathrm{ect}$ ) -Fc-treated rats (Ecto) exhibit a high density of sprouting from the lesioned dCST. Increased numbers of CST fibers are observed in the caudal spinal cord, particularly in gray matter. Parasagittal sections immunostaining for astrocytic marker GFAP from the same animals demonstrate that the transection lesion extends beyond the central canal area in these examples. The injury site is indicated with an arrow. $B$, The dorsoventral linear extent of transected and spared spinal cord measured from consecutive parasagittal sections of each animal ( $n=6$ in each group). $C, D, S c h e m a t i c$ drawing of a transverse and sagittal spinal cord displays the location of sections shown in E.E, F, A composite sagittal section containing the lesion area (arrow) from a $\mathrm{NgR}(310)$ ecto-Fc-treated rat illustrates a BDA-HRP-labeled dCST regenerating axon (dark) projects into distal spinal cord through the spared ventral spinal cord bridging tissue. A higher-magnification image is shown in $F$. G-l, Parasagittal sections containing the transection site (arrows) from a $\mathrm{NgR}(310)$ ecto-Fc-treated rat illustrates the transection of BDA-labeled dCST fibers and some branched, sprouting fibers caudal to the over-hemisection site. Higher-magnification images of these areas in $H$ and $/$ demonstrate the meandering course of the regenerating CST fibers. Scale bars: $A, 1 \mathrm{~mm} ; E, G, 250 \mu \mathrm{m} ; F, H, I, 25 \mu \mathrm{m}$.

lesion and 15 traced axons at $7-8 \mathrm{~mm}$ distal to the lesion from $\mathrm{NgR}(310)$ ecto-Fc-treated rats (Fig. 4D). In one example of $\mathrm{dCST}$ regeneration, a fiber is seen to bypass the lesion site ventrally and extend into the caudal gray matter (Fig. $3 C-F$ ). However, in the vast majority of cases, the origin of caudal fibers in treated animals could not be reconstructed. It is plausible that a subset of caudal sprouting fibers in $\mathrm{NgR}(310)$ ectoFc-treated rats are derived from the vCST. The documented increase of caudal CST fiber counts in the treated rats may 



Figure 4. CST fibers in the caudal spinal cord of $\mathrm{NgR}(310)$ ecto-Fc-treated rats. $A, B$, Parasagittal sections of the distal spinal cord from different $\mathrm{NgR}$ (310)-Fc-treated rats show CST fibers with a highly branched pattern. C, Parasagittal section of the distal spinal cord from an NEP1-40-treated rat illustrates regenerating fibers with a lesser degree of branch complexity. D, CST fiber number at various distances caudal to the injury site from $\mathrm{NgR}(310)$ ecto- $\mathrm{Fc}(n=6$ rats) and control ( $\mathrm{Ctrl} ; n=6$ rats) animals is reported. $E$, Counts of fibers (number of fibers $\geq 200 \mu \mathrm{m}$ in length per rat) outside of the vCST from sagittal sections $1-10 \mathrm{~mm}$ caudal to SCl show a greater number in the $\mathrm{NgR}$ (310)ecto-Fc-treated ( $n=6$ rats) and NEP1-40-treated groups ( $n=7$ rats) than in the control group ( $n=6$ rats). F, CST sprout complexity (total length of fiber arbor per sprout as visualized in a single section) is quantitated for vehicle-treated ( $n=7$ rats), $\mathrm{NgR}(310)$ ecto-Fc-treated ( $n=7$ rats), and NEP1- 40 -treated ( $n=7$ rats) rats. The arbor length per sprout in both sets of $\mathrm{NgR}$ antagonist-treated rats is much greater than control rats. The difference between $\mathrm{NgR}(310)-\mathrm{Fc}$ and NEP1-40 is significant ( $p<0.01$; Student's $t$ test). $G, H$, Transverse section at a level 11-15 mm caudal to the lesion from an $\mathrm{NgR}$ (310)ecto-Fc-treated rat illustrates a number of CST fibers with branching patterns in caudal spinal cord gray matter $(G)$ and white matter $(H)$. I, Quantification of CST fibers from transverse sections $11-15 \mathrm{~mm}$ distal to the lesion indicates a greater number BDA-labeled fibers in $\mathrm{NgR}(310)$ ecto-Fc-treated $(n=6$ rats) and NEP1-40-treated ( $n=7$ rats) animals than the in control group $(n=6)$. Scale bar: $A-C, G, H, 25 \mu \mathrm{m}$. Means + SEM in bar graphs are reported. The values from the $\mathrm{NgR}(310)$ ecto-Fc- or NEP1-40-treated group are statistically different from the control group $(D, E, I)\left({ }^{*} p<0.05 ;{ }^{* *} p<0.01\right.$; Student's $t$ test).

reflect a combination of both axotomized CST fibers that grow into the distal cord plus new sprouts from the vCST that are produced in the presence of $\mathrm{NgR}(310)$ ecto-Fc.

Generally, the number of sprouting CST fibers is similar to that observed from local NEP1-40 peptide-treated animals (Fig. $4 C$ ), but a greater collateral branching from each sprout is seen in the sections from animals treated with $\mathrm{NgR}(310)$ ecto-Fc protein (Fig. $4 A, B$ ). An assessment of sprout complexity demonstrates that the total collateral length of each sprout in $\mathrm{NgR}(310)$ ectoFc-treated rats is twice as great as that from NEP1-40-treated animals (Fig. $4 F$ ). The number of sprouts ( $\geq 200 \mu \mathrm{m}$ in length) at 1-10 mm caudal to the spinal cord in both NgR antagonisttreated groups is $\sim 20-40$ times greater than control groups (Fig. $4 E)$. More sprouts are seen from $\mathrm{NgR}(310)$ ecto-Fc-treated rats than with local NEP1-40 treatment ( $\sim 50$ vs 25 sprouts/rat), but this difference does not reach statistical significance.

Sprouting CST axons are observed in transverse sections of the spinal cord 11-15 mm caudal to over-hemisection in rats receiving $\mathrm{NgR}$ (310)ecto-Fc treatment (Fig. 4G-I). These fibers are detected in both the gray matter (Fig. $4 G$ ) and the white matter (Fig. $4 H$ ) of the spinal cord. The fibers detected in gray matter often exhibit more collateral branching than in white matter area. In contrast, in transverse sections from the vehicle-treated group, only very rare BDA-labeled fibers are seen in the ventral white matter area, consistent with the uninjured vCST axons. At this level of the distal spinal cord, the average number of BDA-labeled CST fibers from both $\mathrm{NgR}$ antagonist-treated groups [NgR(310)ecto-Fc and NEP1-40] are $\sim 20$-fold greater than vehicle-treated rats (Fig. 4I). Both Nogo receptor antagonists, NgR(310)ecto-Fc protein and NEP1-40 peptide, result in dramatic CST axon growth in the caudal spinal cord, but the sprouting induced by the former exhibits a more highly branched pattern.

Do sprouting CST fibers contribute to synaptic connections with motor neurons in the caudal spinal cord? BDA-positive varicosities in the caudal spinal cord were examined for colocalization of the synaptic marker synaptophysin (Fig. 5A). In transverse sections from control animals, BDA-traced CST fibers are extremely rare caudal to the injury, and few BDA-synaptophysin double-positive puncta are observed (Fig. 5B). In contrast, BDA-synaptophysin double-labeled varicosities are commonly seen in the $\mathrm{NgR}(310)$ ectoFc-treated samples with 16-58 examples detected in each section (Fig. 5A,B). Moreover, BDA-traced CST fibers are frequently in close apposition to ventral motor neurons, as detected by staining with SMI-32 anti-neurofilament antibody (Fig. $5 C, D)$. Thus, sprouting CST axons induced by NgR antagonist protein treatment appear to contribute to synaptic innervation in the lumbar spinal cord.

\section{$\mathrm{NgR}(310)$ ecto-Fc induces sprouting and synaptic connection of serotonergic axons}

Several descending pathways contribute to the degree of locomotor function after SCI. The raphespinal system was also examined in $\mathrm{NgR}(310)$ ecto-Fc-treated spinal injured rats. Immunostaining demonstrates a density of serotonergic fibers $11-16 \mathrm{~mm}$ rostral to the lesion that is similar in the vehicle- and $\mathrm{NgR}(310)$ ecto-Fctreated groups. In the sections $17-20 \mathrm{~mm}$ below the lesion, serotonin fibers in $\mathrm{NgR}(310)$ ecto-Fc-treated rats are four times as numerous as those in the control group (Fig. $5 E, F, H$ ). More importantly, the formation of serotonergic synaptic contacts defined by 5 -HT-synpatophysin-positive varicosities in the ventral horn is increased fivefold by $\mathrm{NgR}(310)$ ecto-Fc treatment (Fig. 5I,J). Because the restoration of raphespinal fiber is essentially complete with either $\mathrm{NgR}(310)$ ecto-Fc or NEP1-40 treatment (GrandPre et al., 2002; Li and Strittmatter, 2003), a comparison of the two reagents by this parameter is not informative. Overall, it is clear that responsiveness to $\mathrm{NgR}(310)$ ecto-Fc treatment is not limited to CST fibers, with at least one other descending tract, the raphespinal, being stimulated to grow by $\mathrm{NgR}$ antagonism. 



Figure 5. Sprouting CST and serotoninergic fibers form synaptic specializations in the lumbar spinal cord. A, Transverse lumbar spinal cord sections from NgR(310)ecto-Fc-treated rats double stained with BDA (red) and synaptophysin (green) illustrate colocalization (arrow) of the synaptic marker with the regenerating CST fibers. $B$, The number of BDA-synaptophysin doubly immunoreactive puncta per section from the lumbar spinal cord is reported for control (Ctrl; $n=6$ rats) and $\mathrm{NgR}(310)$ ecto-Fc ( $n=8$ rats) animals. C, D, Transverse sections from $\mathrm{NgR}(310)$ ecto-Fc-treated rats stained with BDA (red) and a motor neuron marker, SMI-32 (green), indicate the close relationship of regenerating CST fibers (arrow) with the lumbar spinal cord motor neurons. $E-G$, Transverse sections of the ventral horn $17-20 \mathrm{~mm}$ caudal to an over-hemisection illustrate the serotonin fibers stained with antibody against 5-HT from vehicle-treated $(E), \mathrm{NgR}(310)$ ecto-Fc-treated $(F)$, and $\mathrm{NgR}(310)$ ecto-Fc plus serotonin neurotoxin DHT-treated $(G)$ rats. $H$, Bar graph indicates the immunoreactive serotonin fiber length in the ventral horn of transverse sections at a level of $11-15 \mathrm{~mm}$ rostral or $17-20 \mathrm{~mm}$ caudal to the injury site ( $n=6$ rats in each group). I, Transverse sections from $\mathrm{NgR}$ (310)ecto-Fc-treated rats immunostained with 5-HT (red) and synaptophysin (green) indicate that synaptophysin is colocalized (arrow) with serotonin fibers in the ventral horn of the lumbar spinal cord. J, Bar graph shows the frequency of colocalized 5-HT plus synaptophysin puncta per transverse sectin of the lumbar ventral horn from control ( $n=7$ rats) and $\mathrm{NgR}(310)$ ecto- $\mathrm{Fc}(n=7 \mathrm{rats})$ animals. Sale bars: $A, C, D, I, 25 \mu \mathrm{m} ; E-G, 50 \mu \mathrm{m}$. The means + SEM in the bar graphs are reported. The values from the $\mathrm{NgR}(310)$ ecto-Fc group are statistically different from control $\left({ }^{* *} p<0.01\right.$; Student's $t$ test).

\section{Local treatment with $\mathrm{NgR}(310)$ ecto-Fc protein improves} functional recovery in rat $\mathrm{SCI}$

Intrathecal administration of $\mathrm{NgR}(310)$ ecto-Fc protein stimulates axon regeneration in several descending pathways after traumatic SCI. Does this protein improve functional recovery in the injured spinal cord? The descending motor system can be assessed noninvasively after transcranial magnetic stimulation with the hindlimb EMG as an output (tcmMEP). In uninjured animals, robust responses are detectable in all rats with a latency of $5.5 \mathrm{msec}$ and an amplitude of $200 \mu \mathrm{V}$ (Fig. 6A-E). Three weeks after dorsal over-hemisection injury, only $60 \%$ of control rats exhibit any tcmMEP. In the subset of animals with a response, the latency is prolonged, amplitude is decreased, and stimulation threshold is increased. All rats exhibit a tcmMEP signal after $\mathrm{NgR}(310)$ ecto-Fc treatment. Moreover, the latency of the response and the threshold for simulation return to preinjury values in the treatment group. Response amplitudes in this group are significantly greater than in vehicle-treated rats but are not as great as in preinjury controls. Electrophysiological assessment of the integrity of descending motor pathways was also assessed under anesthesia before the rats were killed by direct stimulation in the upper thoracic spinal cord (SCEP) (Fig. 6F-I). Through a laminectomy, the spinal cord was directly stimulated at a depth corresponding to the dCST. Reponses were recorded from the sciatic nerve. Only half of the vehicle-treated spinal-injured rats exhibited a SCEP, whereas all of the NgR(310)ecto-Fc-treated animals had detectable potentials. In addition, the treated group exhibited significantly shorter SCEP latencies and greater amplitudes. Thus, the anatomical fiber growth and synaptic terminals translate into electrophysiological evidence of motor function recovery.

Locomotor performance was assessed at several time points after injury (Fig. 7). At 2 weeks after the over-hemisection, the locomotor BBB score in vehicle-treated rats begins to plateau, reaching a level of 11-12 (Fig. 7A-C). At 4 weeks after the lesion, most of the controls (six of seven in experiment A) have frequent consistent weight-supported plantar steps and frequent consistent forelimb-hindlimb coordination, but they rotate the paw when making initial contact with the floor. In contrast, in rats receiving $\mathrm{NgR}(310)$ ecto-Fc protein treatment, the locomotor score continues to improve more dramatically between 2 and 4 weeks after trauma to a level that is significantly better than in the controls in multiple experiments (Fig. 7A-C). At 4 weeks after SCI, all nine of the $\mathrm{NgR}(310)$ ecto-Fc-treated animals in experiment A had consistent forelimb-hindlimb coordination and a parallel paw position at initial contact with the testing surface. The beneficial effect of $\mathrm{NgR}(310)$ ecto-Fc was observed in several independent cohorts of rats (Fig. $7 A-C$ ). This effect is dose dependent, in that a 10 -fold reduction in the dose of $\mathrm{NgR}(310)$ ecto-Fc limits the improvement in $\mathrm{BBB}$ scores by $50 \%$, producing a benefit that is not significantly different from control values (data not shown).

Grid walking has been used to assess the deficits in descending fine motor control after SCI (Metz et al., 2000). This performance requires forelimb-hindlimb coordination and voluntary movement integration mediated by raphespinal, corticospinal, vestibulospinal, and rubrospinal fibers. During the preinjury training, all rats accurately place their hindlimbs on the grid bars. At 2-4 weeks after injury, control rats make eight to nine errors per session with only minimal improvement over time. In contrast, the rats treated with $\mathrm{NgR}(310)$ ecto-Fc exhibit a progressive improvement on grid walking and make significantly fewer errors (four to seven per session, on average). The majority of the improvement occurs at 2-3 weeks after SCI (Fig. $7 F$ ). Analysis of 


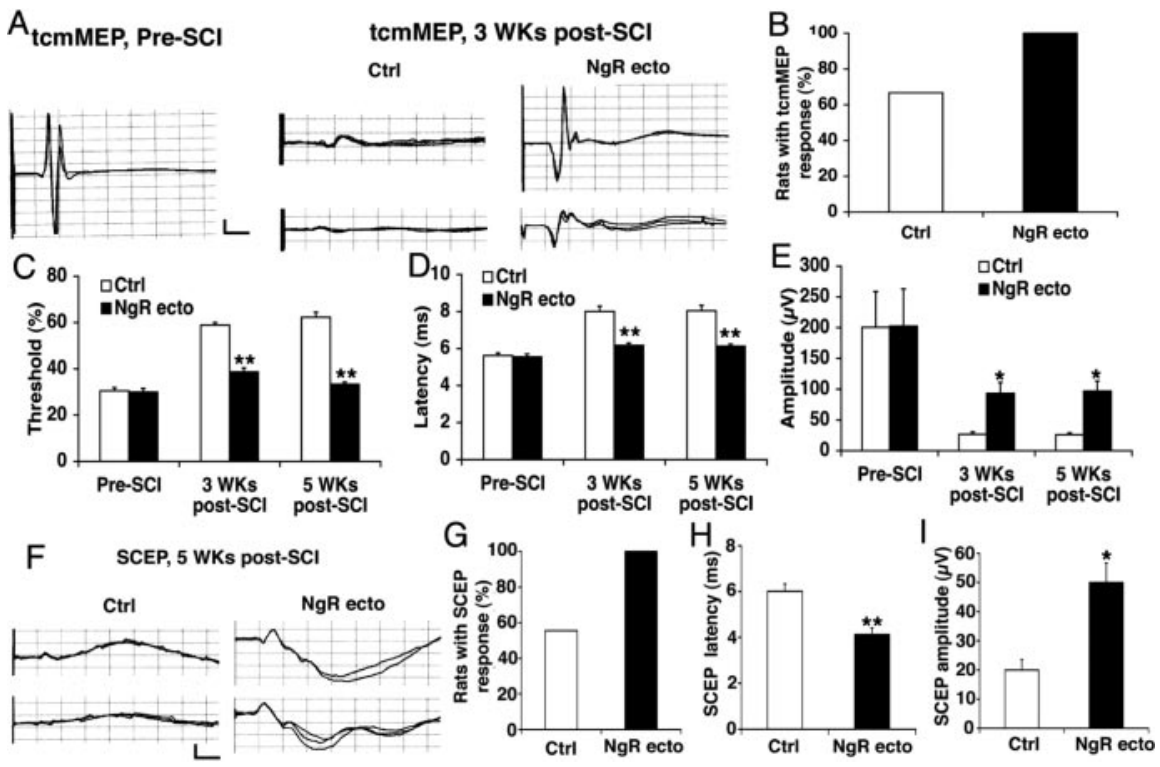

Figure 6. Intrathecal delivery of $\mathrm{NgR}(310)$ ecto- $\mathrm{Fc}$ promotes signal conduction in injured spinal cord. $A$, Representative tcmMEP responses recorded from one pre-SCl rat, two control rats, and two $\mathrm{NgR}(310)$ ecto- $\mathrm{Fc}$ rats 3 weeks after $\mathrm{SCl}$ by transcranial magnetic stimulation. Calibration: $5 \mathrm{msec}, 50 \mu \mathrm{V}$. B, A tcmMEP response was detected from all the rats treated with $\mathrm{NgR}(310)$ ecto-Fc protein ( $n=18$ legs from 9 rats) but were recorded from only $64 \%$ of rats in the control group ( $n=18$ legs from 9 rats) 5 weeks after injury. $(-E$, Bar graphs indicate the stimulation threshold $(C)$, onset latency $(D)$, and amplitude $(E)$ for tcmMEP recorded from the preinjury rats ( $n=12$ legs from 6 rats), control SCl rats ( $n=12$ legs from 6 rats), and $\mathrm{NgR}(310)$ ectoFc-treated rats ( $n=18$ legs from 9 rats) 5 weeks after $S C$ I. The stimulation threshold is reported as a percentage of maximal power delivered to the magnetic coil. F, Representative SCEP responses recorded from two control and two $\mathrm{NgR}(310)$ ecto-Fc rats 5 weeks after SCI with electrical stimulation of dCST area at T1 spinal level. Calibration: $5 \mathrm{msec}, 50 \mu \mathrm{V}$. G, The SCEP responses were recorded from all the rats receiving $\mathrm{NgR}(310)$ ecto-Fctreatment ( $n=9$ rats) but were only recorded in $55 \%$ of rats treated with vehicle ( $n=$ 9 rats) 5 weeks after SCI. $H, I$, Bar graphs indicate the onset latency $(H)$ and amplitude $(I)$ of SCEP from control rats $(n=5$ rats) and $\mathrm{NgR}(310)$ ecto-Fc-treated rats ( $n=9$ rats) 5 weeks after the lesion. Means $+S E M$ are reported in all the graphs. The values of the $\mathrm{NgR}(310)$ ecto-Fc group are statistically different from control $\left({ }^{*} p<0.05\right.$; ${ }^{* *} p<0.01$; Student's $t$ test).

hindpaw footprints in the control group demonstrates decreased stride length and increased stance width at 4 weeks after overhemisection, compared with uninjured rats or SCI animals receiving $\mathrm{NgR}(310)$ ecto-Fc treatment (Fig. 7 D,E). Therefore, multiple behavioral tests demonstrate that blockade of $\mathrm{NgR}$ function with local infusion of antagonist protein improves locomotor recovery after SCI.

Because anatomical studies demonstrate growth of both CST and serotonergic fibers after $\mathrm{NgR}(310)$ ecto-Fc treatment, the locomotor improvement might be attributable to one or both fiber systems. To assess whether the presence of 5-HT axons is necessary for the improved function, neurotoxin studies were performed in treated and control spinal-injured rats. DHT was administered intracerebroventricularly to selectively lesion serotonergic neurons. Animals were pretreated with desipramine to protect catecholaminergic neurons. The loss of 5-HT fibers from treated rats was verified histologically (Fig. 5G,H). Serotonergic lesioning at 3 weeks after SCI did not alter the performance of control spinal-injured rats as measured by the BBB score or by their ability to ascend a smooth inclined plane (Fig. 7G,H). A group of $\mathrm{NgR}(310)$ ecto-Fc-treated rats performed significantly better than control animals on these tests before DHT treatment, and the DHT lesion reduced their superiority over control rats. This demonstrates that the presence of a raphespinal system, which is induced to grow by $\mathrm{NgR}(310)$ ecto-Fc treatment (Fig. $5 E, F, H)$, is necessary for some, but not all, of the locomotor improvement observed in $\mathrm{NgR}(310)$ ecto-Fc animals.

\section{Discussion}

From in vitro studies, the $\mathrm{NgR}$ has been shown to constitute a site of signal convergence for three axon inhibitory proteins found in CNS myelin (McGee and Strittmatter, 2003). We blocked NgR-dependent signaling in adult rodents by mechanical delivery of a soluble version of the $\mathrm{NgR}$. This allows an assessment of the significance of summated inhibition from Nogo-66, MAG, and OMgp. The soluble fragment of the NgR almost certainly acts as a decoy receptor, creating a fruitless complex that cannot signal into the axonal cytoplasm to limit axonal extension (Fournier et al., 2002; Liu et al., 2002; Barton et al., 2003). The blockade of signaling by soluble $\mathrm{NgR}(310)$ ecto is most likely to involve sequestration of ligand from endogenous active glycophosphatidylinositol (GPI)-linked NgR. Because soluble $\mathrm{NgR}(310)$ ecto can bind to membraneassociated NgR, this may provide an additional mechanism for the soluble receptor fragment to disrupt signaling function (Fournier et al., 2002; Liu et al., 2002). However, the much lower affinity of $\mathrm{NgR}$ $\mathrm{NgR}$ interactions compared with NgR-ligand renders this second mechanism unlikely.

\section{$\operatorname{NgR(310)ecto-stimulated~growth~in~}$ multiple pathways}

The NgR protein is widely expressed in the adult brain with most, but not all, neurons expressing the protein (Hunt et al., 2002; Josephson et al., 2002, 2003; X. Wang et al., 2002c). Likewise, multiple fiber tracts that normally contribute to locomotor function are susceptible to spinal cord trauma (Raineteau and Schwab, 2001; Bareyre et al., 2004). The descending CST has the longest trajectory and has been the focus of study in numerous previous SCI studies. In untreated wild-type animals, mid-thoracic spinal trauma is not associated with significant sprouting or long-distance growth (GrandPre et al., 2002; Kim et al., 2003), although a modest degree of local sprouting from uninjured fibers has been observed (Weidner et al., 2001). Here, significant CST sprouting rostral to the injury is observed in the presence of dominant-negative $\mathrm{NgR}(310)$ ecto. Some CST fiber branches meander around the lesion site and follow a tortuous course in the caudal spinal cord. Although the number of growing fibers is far greater than in control cases, it is also far less than the number observed in uninjured animals. Increased fiber density extends into the caudal spinal cord for at least 4-8 $\mathrm{mm}$. Because the efficiency of BDA labeling in the CST is 1-2\% (Brosamle and Schwab, 1997), the observation of 30 BDA-labeled CST fibers is likely to represent a total of 2000 CSTs innervating the caudal spinal cord under the influence of $\mathrm{NgR}(310)$ ecto-Fc. From ultrastructural studies, a value of 2000 lumbar CST fibers would comprise $\sim 5 \%$ of the normal innervation density (Leenen et al., 1985). Consistent with this estimate, our BDA-labeling method detects $\sim 300$ BDAlabeled CST fibers in the upper thoracic cord of rats rostral to a SCI site (GrandPre et al., 2002). 
Another descending fiber system studied here, the serotonergic raphespinal system, is partially damaged in this surgery. In the presence of the soluble $\operatorname{NgR}(310)$ ecto protein, the 5-HT fiber density in the lumbar ventral horn of the caudal spinal cord increases greatly, returning to levels indistinguishable from that in uninjured animals. Thus, at least two descending fiber systems damaged in this dorsal overhemisection model exhibit regenerative growth in the spinal cord in the presence of the function-blocking $\mathrm{NgR}(310)$ ecto soluble protein. The extent of growth is much different from control animals and ranges from complete restitution of fiber density to only partial restoration of prelesion axon density.

\section{Specificity of axon growth and synaptic connections}

When certain degrees of sprouting and fiber growth are observed after injury, it is critical to consider whether these fibers target to appropriate sites. For the 5-HT system, there is a low density of fibers remaining after injury that is situated in the correct target area. Therefore, local sprouting from remaining axons requires little guidance to generate appropriate regional localization of innervation, as was observed here. CST fibers are faced with more challenging guidance issues. It is clear that the course of those fibers that sprout rostral to the injury create novel paths not present in the uninjured animals. Distal to the injury, those CST fibers observed in the soluble NgR(310)ecto-Fctreated rats and $\mathrm{NgR}(310)$ ecto-expressing mice follow trajectories very different from the CST of uninjured animals. Their course is not linear and not confined to the typical white matter location. Thus, the guidance of such fibers does not recapitulate the course that these fibers follow during development. Still, a number of fibers reach the distal spinal cord. Both the sprouting serotonergic and CST fibers ex-

hibit anatomical specializations consistent with synaptic formation. It is conceivable that suprasegmental input, even without topographic precision, may contribute to neuronal function. A delineation of the precision of synaptic connectivity will require electrophysiological mapping from discrete supraspinal territories and has not yet been determined for these fibers growing in the presence of soluble $\mathrm{NgR}(310)$ ecto protein. However, from the tcmMEP and SCEP measurements, it is clear that $\mathrm{NgR}(310)$ ecto-Fc treatment promotes a degree of electrophysiological connectivity in descending motor pathways.

\section{Locomotor recovery}

The dorsal over-hemisection destroys a proportion of supraspinal input to the lumbar spinal cord and produces significant, but incomplete, loss of hindlimb function during locomotion. The


Figure 7. Intrathecal $\mathrm{NgR}(310)$ ecto-Fc improves behavioral recovery after rat dorsal over-hemisection. $A-C$, The locomotor BB score is reported as a function of time after dorsal over-hemisection in the vehicle- or NgR(310)ecto-Fc-treated rats from thre F. For example, the $21 \mathrm{~d}$ BBB control score was $12.5 \pm 0.9$, and the $\mathrm{NgR}(310)$ ecto-Fc score was $15.5 \pm 0.2(p<0.01)$ $A$ ( $n=7-9$ rats per group) was performed at Yale University, experiment $B$ was performed at Biogenldec

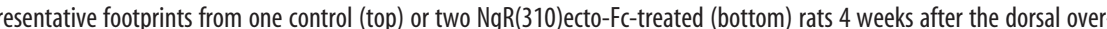
, Footprint analysis reveals a shorter stride length and a greater stride width in control rats ( $n=7$ rats) than in

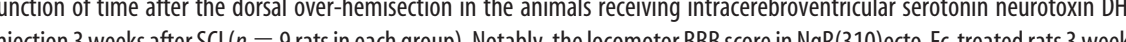
after $\mathrm{SCl}$ was significantly decreased after DHT administration. $H$, The maximal tolerated inclined plane angle is reported as a function of time after $\mathrm{SCl}$ from these rats receiving intracerebroventricular DHT injections ( $n=9$ rats in each group). The inclined plane angle in $\mathrm{NgR}$ (310)ecto-Fc-treated rats was significantly decreased at 4 weeks after injury because of DHT application. Means $A$ and $F-H$. The control IgG treatment values are statistically different from no-SCl or SCl plus NgR(310)ecto-Fc rats in $E$. In $G$ and $H$, the 28 and 35 d values for the $\mathrm{NgR}(310)$ ecto-Fc-treated rats were significantly different from the same animals at day 21 before DHT. $\left(^{*} p<0.05 ;{ }^{* *} p<0.01\right.$; Student's $t$ test).

partial recovery of function in control animals may be attributed to distal rearrangements of those descending fibers spared at the time of the initial lesion and to the function of distal circuits in the absence of suprasegmental input. Recently, it has been demonstrated that local plasticity after SCI creates new circuits between descending CST fibers and cervical propriospinal neurons (Bareyre et al., 2004).

In animals receiving the function-blocking soluble $\mathrm{NgR}(310)$ ecto, the recovery of locomotor function is improved by several measures, including the BBB open-field score, a grid walking task, and by stride length analysis. There are several potential mechanisms for this improvement. The raphespinal system is necessary for a proportion of the improvement, as documented by selective neurotoxin lesioning. However, the raphespinal fiber response to $\mathrm{NgR}(310)$ ecto-Fc does not appear 
to be sufficient for the improved function. The role of spinal serotonin levels in facilitating spinal locomotor function in both rodents and humans is well documented (Saruhashi et al., 1996; Schmidt and Jordan, 2000). The recovery of the tcmMEP and the SCEP in the NgR(310)ecto-Fc-treated animals suggests that CST fiber growth into the lumbar cord also plays an important role in the recovery. Although the plasticity of connections among interneurons localized in the distal spinal cord has not been characterized here, this remains an additional site where increased fiber growth might contribute to functional recovery. The inherent plasticity of the injured spinal cord in forming new circuitry (Bareyre et al., 2004) may be enhanced by $\mathrm{NgR}(310)$ ecto-Fc.

\section{Comparison with other NgR antagonists}

In previous studies, a peptide antagonist of Nogo-66 was identified. This subfragment of Nogo-66 binds to NgR and blocks Nogo action, but not MAG or OMgp action. When infused into the injured rat spinal cord, the NEP1-40 antagonist peptide promotes CST and raphespinal axon sprouting and fiber growth as well as locomotor recovery (GrandPre et al., 2002). The NgR protein reagent in this study blocks Nogo-66, MAG, and OMgp function. Therefore, a comparison of the two studies can be considered as a means to assess the relative roles of Nogo-66 versus MAG and OMgp. Thus, the modest increase in sprouting complexity and in fiber number seen for CST fibers in the current study may reflect the contribution of MAG and OMgp. Despite greater CST sprouting, NgR(310)ecto-Fc does not produce a degree of locomotor recovery that is signficantly different from that caused by NEP1-40 treatment (GrandPre et al., 2002).

Viral-mediated expression of the dominant-negative membrane-bound NgR fragment has been shown to enhance optic nerve regeneration (Fischer et al., 2004). In the case of retinal ganglion cells, axonal growth with $\mathrm{NgR}$ antagonism alone was minor, unless an enhanced growth state was enhanced by lens injury. In such a state, the effect of dominant-negative $\mathrm{NgR}$ was pronounced. In the current study, no adjunctive treatment was administered to enhance a moderate degree of axonal growth. It may be that axonal growth after SCI would be more complete if $\mathrm{NgR}$ antagonism were combined with agents mimicking the effects of lens injury on retinal ganglion cells.

\section{Conclusion and perspectives}

The NgR(310)ecto-Fc protein provides blockade of several CNS myelin inhibitors in vitro. When delivered by pharmacological means, the protein supports CST and raphespinal axon growth in vivo with improved functional recovery from SCI. These data suggest that function-blocking $\mathrm{NgR}$ protein preparations have potential clinical use. Alternative mechanisms of achieving the similar beneficial effects after CNS injury might include anti-NgR antibody reagents. The recent determination of the structure of the $\operatorname{NgR}(310)$ ecto ligand-binding domain (Barton et al., 2003; He et al., 2003) could potentially facilitate the rational design of small molecule $\mathrm{NgR}$ antagonists.

SCI is perhaps the clearest example of a clinical condition in which few neurons are lost but axonal discontinuity is the basis of functional deficits. However, many other neurological conditions result, at least in part, from axonal disconnection. Such conditions include head trauma, stroke, and chronic progressive multiple sclerosis. The promotion of adult CNS axon growth may alleviate deficits in any or all of these conditions.

\section{References}

Bareyre FM, Kerschensteiner M, Raineteau O, Mettenleiter TC, Weinmann O, Schwab ME (2004) The injured spinal cord spontaneously forms a new intraspinal circuit in adult rats. Nat Neurosci 7:269-277.

Barton WA, Liu BP, Tzvetkova D, Jeffrey PD, Fournier AE, Sah D, Cate R, Strittmatter SM, Nikolov DB (2003) Structure and axon outgrowth inhibitor binding of the Nogo-66 receptor and related proteins. EMBO J 22:3291-3302.

Bradbury EJ, Moon LD, Popat RJ, King VR, Bennett GS, Patel PN, Fawcett JW, McMahon SB (2002) Chondroitinase ABC promotes functional recovery after spinal cord injury. Nature 416:636-640.

Bregman BS, Kunkel-Bagden E, Schnell L, Dai HN, Gao D, Schwab ME (1995) Recovery from spinal cord injury mediated by antibodies to neurite growth inhibitors. Nature 378:498-501.

Brosamle C, Schwab ME (1997) Cells of origin, course, and termination patterns of the ventral, uncrossed component of the mature rat corticospinal tract. J Comp Neurol 386:293-303.

Curristin SM, Cao A, Stewart WB, Zhang H, Madri JA, Morrow JS, Ment LR (2002) Disrupted synaptic development in the hypoxic newborn brain. Proc Natl Acad Sci USA 99:15729-15734.

Davies SJ, Goucher DR, Doller C, Silver J (1999) Robust regeneration of adult sensory axons in degenerating white matter of the adult rat spinal cord. J Neurosci 19:5810-5822.

Dergham P, Ellezam B, Essagian C, Avedissian H, Lubell WD, McKerracher L (2002) Rho signaling pathway targeted to promote spinal cord repair. J Neurosci 22:6570-6577.

Domeniconi M, Cao Z, Spencer T, Sivasankaran R, Wang K, Nikulina E, Kimura N, Cai H, Deng K, Gao Y, He Z, Filbin M (2002) Myelinassociated glycoprotein interacts with the Nogo66 receptor to inhibit neurite outgrowth. Neuron 35:283-290.

Fischer D, He Z, Benowitz LI (2004) Counteracting the Nogo receptor enhances optic nerve regeneration if retinal ganglion cells are in an active growth state. J Neurosci 24:1646-1651.

Fournier AE, GrandPre T, Strittmatter SM (2001) Identification of a receptor mediating Nogo-66 inhibition of axonal regeneration. Nature 409:341-346.

Fournier AE, Gould GC, Liu BP, Strittmatter SM (2002) Truncated soluble Nogo receptor binds Nogo-66 and blocks inhibition of axon growth by myelin. J Neurosci 22:8876-8883.

Fournier AE, Takizawa BT, Strittmatter SM (2003) Rho kinase inhibition enhances axonal regeneration in the injured CNS. J Neurosci 23:1416-1423.

GrandPre T, Li S, Strittmatter SM (2002) Nogo-66 receptor antagonist peptide promotes axonal regeneration. Nature 417:547-551.

He XL, Bazan JF, McDermott G, Park JB, Wang K, Tessier-Lavigne M, He Z, Garcia KC (2003) Structure of the Nogo receptor ectodomain: a recognition module implicated in myelin inhibition. Neuron 38:177-185.

Hunt D, Mason MR, Campbell G, Coffin R, Anderson PN (2002) Nogo receptor mRNA expression in intact and regenerating CNS neurons. Mol Cell Neurosci 20:537-552.

Josephson A, Trifunovski A, Widmer HR, Widenfalk J, Olson L, Spenger C (2002) Nogo-receptor gene activity: cellular localization and developmental regulation of mRNA in mice and humans. J Comp Neurol 453:292-304.

Josephson A, Trifunovski A, Scheele C, Widenfalk J, Wahlestedt C, Brene S, Olson L, Spenger C (2003) Activity-induced and developmental downregulation of the Nogo receptor. Cell Tissue Res 311:333-342.

Kim JE, Li S, GrandPre T, Qiu D, Strittmatter SM (2003) Axon regeneration in young adult mice lacking Nogo-A/B. Neuron 38:187-199.

Leenen LP, Meek J, Posthuma PR, Nieuwenhuys R (1985) A detailed morphometrical analysis of the pyramidal tract of the rat. Brain Res 359:65-80.

Li S, Strittmatter SM (2003) Delayed systemic Nogo-66 receptor antagonist promotes recovery from spinal cord injury. J Neurosci 23:4219-4227.

Liu BP, Fournier A, GrandPre T, Strittmatter SM (2002) Myelin-associated glycoprotein as a functional ligand for the Nogo-66 receptor. Science 297:1190-1193.

McGee AW, Strittmatter SM (2003) The Nogo-66 receptor: focusing myelin inhibition of axon regeneration. Trends Neurosci 26:193-198.

Metz GA, Merkler D, Dietz V, Schwab ME, Fouad K (2000) Efficient testing of motor function in spinal cord injured rats. Brain Res 883:165-177.

Mi S, Lee X, Shao Z, Thill G, Ji B, Relton J, Levesque M, Allaire N, Perrin S, 
Sands B, Crowell T, Cate RL, McCoy JM, Pepinsky RB (2004) LINGO-1 is a component of the Nogo-66 receptor/p75 signaling complex. Nat Neurosci 7:221-228.

Neumann S, Bradke F, Tessier-Lavigne M, Basbaum AI (2002) Regeneration of sensory axons within the injured spinal cord induced by intraganglionic cAMP elevation. Neuron 34:885-893.

Nikulina E, Tidwell JL, Dai HN, Bregman BS, Filbin MT (2004) The phosphodiesterase inhibitor rolipram delivered after a spinal cord lesion promotes axonal regeneration and functional recovery. Proc Natl Acad Sci USA 101:8786-8790.

Pearse DD, Pereira FC, Marcillo AE, Bates ML, Berrocal YA, Filbin MT, Bunge MB (2004) cAMP and Schwann cells promote axonal growth and functional recovery after spinal cord injury. Nat Med 10:610-616.

Qiu J, Cai D, Dai H, McAtee M, Hoffman PN, Bregman BS, Filbin MT (2002) Spinal axon regeneration induced by elevation of cyclic AMP. Neuron 34:895-903.

Raineteau O, Schwab ME (2001) Plasticity of motor systems after incomplete spinal cord injury. Nat Rev Neurosci 2:263-273.

Saruhashi Y, Young W, Perkins R (1996) The recovery of 5-HT immunoreactivity in lumbosacral spinal cord and locomotor function after thoracic hemisection. Exp Neurol 139:203-213.

Savio T, Schwab ME (1989) Rat CNS white matter, but not gray matter, is nonpermissive for neuronal cell adhesion and fiber outgrowth. J Neurosci 9:1126-1133.

Schmidt BJ, Jordan LM (2000) The role of serotonin in reflex modulation and locomotor rhythm production in the mammalian spinal cord. Brain Res Bull 53:689-710.

Schnell L, Schwab ME (1990) Axonal regeneration in the rat spinal cord produced by an antibody against myelin-associated neurite growth inhibitors. Nature 343:269-272.

Schwab ME, Caroni P (1988) Oligodendrocytes and CNS myelin are nonpermissive substrates for neurite growth and fibroblast spreading in vitro. J Neurosci 8:2381-2393.

Snow DM, Lemmon V, Carrino DA, Caplan AI, Silver J (1990) Sulfated proteoglycans in astroglial barriers inhibit neurite outgrowth in vitro. Exp Neurol 109:111-130.

Wang KC, Koprivica V, Kim JA, Sivasankaran R, Guo Y, Neve RL, He Z (2002a) Oligodendrocyte-myelin glycoprotein is a Nogo receptor ligand that inhibits neurite outgrowth. Nature 417:941-944.

Wang KC, Kim JA, Sivasankaran R, Segal R, He Z (2002b) p75 interacts with the Nogo receptor as a co-receptor for Nogo, MAG and OMgp. Nature 420:74-78.

Wang X, Chun SJ, Treloar H, Vartanian T, Greer CA, Strittmatter SM (2002c) Localization of Nogo-A and Nogo-66 receptor proteins at sites of axon-myelin and synaptic contact. J Neurosci 22:5505-5515.

Weidner N, Ner A, Salimi N, Tuszynski MH (2001) Spontaneous corticospinal axonal plasticity and functional recovery after adult central nervous system injury. Proc Natl Acad Sci USA 98:3513-3518.

Wong ST, Henley JR, Kanning KC, Huang KH, Bothwell M, Poo MM (2002) A p75(NTR) and Nogo receptor complex mediates repulsive signaling by myelin-associated glycoprotein. Nat Neurosci 5:1302-1308. 